\title{
Maximize Utilization From Fertigation Management For Snap Bean (Phaseolus Vulgaris L.) Under Sandy Soil
}

\author{
${ }^{1}$ Sabreen, Kh. Pibars, ${ }^{2}$ Mansour, H. A.*, ${ }^{3}$ M. Abd El-Hady \\ and ${ }^{4}$ Ebtisam I. Eldardiry \\ ${ }^{1,2,3,4}$ Water Relations and Field Irrigation Dept., Agricultural Division \& National Research Centre, Egypt.
}

\begin{abstract}
Field experiment was conducted during the summer seasons of 2012 and 2013 at the Research and Production Station, National Research Centre, Nubaria region, Behera Governorate, Egypt to study the effect of (Fertigation/irrigation time ratio) fertigation time relative to the irrigation process time and type of fertilizers used on the water distribution uniformity and yield and water use efficiency and fertilizer use efficiency of the some macronutrients ( $N, P$ and $K$ ) of snap bean (Phaseolus vulgaris L. cv. Bronco) planted in sandy soil.

The results could be summarized in the following: completely soluble fertilizers produced higher yield comparing with traditional fertilizers under different modern chemigation systems, whereas drip irrigated snap bean crop produced $20.1 \%$ more in yield, by using completely soluble fertilizers comparing with solid one. The highest snap bean yield was 4.93 Ton/fed using completely soluble fertilizer.

Clogging values under traditional fertilizers could be arranged in ascending order as follow: $2 / 3<3 / 4<1 / 2$ fertigation time. Highly positively relation was obtained between them with highly correlation $\left(0.956^{* *}\right)$. It is clear that highly soluble fertilizer when time of fertigation resembles $3 / 4$ from irrigation time fulfil the maximum yield. Significantly higher yield was observed with increasing fertigation time, where increasing fertigation time by about 10 minutes increased yield by about $12 \%$ (from 2/3 to 3/4 fertigation time) under completely soluble fertilizers. Under traditional fertilizers, the opposite was true and the reduction was $6.5 \%$ in same sequence. Also, injection fertilizer period $3 / 4$ was superior under completely soluble fertilizers while $2 / 3$ fertigation time was the best under traditional ones. Regardless fertilizers type, FUE values of ferigation time could arrange in descending order as follow: $3 / 4>2 / 3>1 / 2$ for $N, P$ and $K$ fertilizers. The percentage of the increase in FUE under fertigation time $3 / 4$ comparing with $2 / 3$ and $1 / 2$ were $3.6,16.6,5.0,16.7$ and 3.5 and $16.6 \%$ for $N, P$ and $K$, respectively. Decreasing fertigation time was associated with decrease in FUE for the studied macronutrients, except under traditional fertilizer types, where fertigation during $2 / 3$ irrigation time was the best one followed by the highest fertigation time (3/4 from irrigation time).
\end{abstract}

Key words: drip irrigation, fertigation, fertilizers, clogging, snap bean, sandy soil.

\section{Introduction}

The agricultural sector in Egypt consumes about more than $81 \%$ from the total water income and about 1.25 million tons of fertilizer annually $(\mathbf{F A O}, \mathbf{2 0 0 5})$. While increasing fertilizers lead to not only soil pollution but also contaminated products are expected. This problem forces the scientists to find out a new technique to overcome reasons of such problem. One of these techniques is using the fertigation system to increase the efficiency of both fertilization and irrigation systems. Drip irrigation systems have the potential advantage of higher efficiency in supplying water and nutrients to plants (Ould Ahmed et al. 2006). In addition water and nutrients can be applied directly to the crop at root level, which reflected directly by positive effects on increasing yield and water saving and thus increase the irrigation performance under field condition. Charles (2007) reported some advantages of fertigation which include easy application, use in adverse factors, low hazards, and conservation of proper soil structure, possible control of pests and weeds and decreasing the adverse effect of salinity. However, the disadvantages of this system include increases in capital expenditure, incidents of orifices clogging, incidents of salinity build-up and need for technical handling.

Efficient use of water in any irrigation system is becoming important particularly in arid and semiarid region where water is a scarce commodity. There are specific problems in the management of sandy soils including their excessive permeability, low water and nutrient holding capacities (Suganya and Sivasamy, 2006). Therefore, the managing is helpful not only is the use of irrigation water but also plant nutrients a major challenge of sandy soil amelioration efforts. Fertilisers suitable for use in fertigation systems come as technical grade salts (e.g. potassium sulphate), acids (e.g. nitric acid), bases (e.g. potassium hydroxide), polymers (e.g. polyphosphate) or chelates (e.g. iron EDTA). They are almost exclusively injected into the irrigation water 
already in solution (i.e. pre-dissolved in water). Hochmuth (1992) reported that to achieving maximum fertigation efficiency requires knowledge of crop nutrient requirements during different growth periods, soil nutrient supply, fertilizer injection technology, irrigation scheduling, crop and soil monitoring techniques. If properly managed, fertigation through drip irrigation lines can reduce overall fertilizer application rates and minimize adverse environmental impact of vegetable production.(Raun and Johnson, 1999).Locascio and Smajstrala, (1995) stated that increase produced higher yield as compared to the fertilizer applied just before planting Snapbean (Phaseolus vulgaris L.) is one of the important pulse crops, grown in Egypt, during the winter season. Higher productivity, nutritive status, less water requirement, greater remunerative value and constant market demand made this crop more popular among the farmers of LGP. Incorporating this crop in the cropping sequence can minimize the irrigation demand on ground water and also improve the soil productivity (Sarkar et al., 2000)

The interaction between water and nutrient is another important aspect of irrigation management to enhance the WUE of any crop. Among three major nutrients (nitrogen, phosphorus and potassium), the least information is available on irrigation water phosphorus interaction, in relation to ET status. Pre-sowing irrigation, combined with phosphorus, enhances root proliferation rate as well as prolongs root growth period, but this effect is not prominent under water scarce situation (Li et al., 2001).

The aim of the work to study the effect of Fertigation / Irrigation time ratio relative to the irrigation process time and type of fertilizers used on the water distribution uniformity and yield and WUE and FUE of the snap bean plants.

\section{Material And Methods}

The experiment was conducted at Research and Production Station, National Research Centre, Nubaria region, Behera Governorate, Egypt, during the summer seasons of 2012/2013. The soil of the experimental site was sand in texture, very poor in organic matter $(0.65 \%)$ with a moderately alkaline $\mathrm{pH}(8.2)$, soil EC $\left(0.35 \mathrm{dS}^{-}\right.$ ${ }^{1}$ ), and $\mathrm{CaCO}_{3}(7.02 \%)$ before the initiation of first year experiment. The field capacity, wilting point and available water values were $11.1,4.7$ and $6.4 \%$ on weight basis, respectively. The source of irrigation water at experimental site is well water with EC $0.39 \mathrm{dSm}^{-1}$ and $\mathrm{pH} 7.63$.

Seeds of snap bean (Phaseolus vulgaris L. cv. Bronco) were sown in the 10 February. Seeds were sown in hills $5-7 \mathrm{~cm}$ apart on two side ridges with the spacing of $90 \mathrm{~cm}$ between the rows and $30 \mathrm{~cm}$ among the drippers in a lateral line. The experiment was laid out in a randomized complete block design having six treatments and triplicated in $5.4 \mathrm{~m} \times 4.8 \mathrm{~m}$ plot. The second year experiment was superimposed on the first year's experimental plots. The crop lasted 118 days in first and second years of study from transplanting to final picking. Flowering stage of snap beans started after about 45 days from planting for both seasons. Harvesting of fresh yield was started 20 days later and 5 days each.

According to the irrigation schedule, author depends mainly on the climatic data, which available from Meteo station in farm of NRC. Table (1) that illustrated the main climatology parameters during two growing seasons and used in calculation of ETo. Soil moisture is kept not less than $60 \%$ from water content at field capacity, where the snap beans is sensitive to drought and water depletion more than $40 \% \mathrm{FC}$ affects negatively on the flowering quantity and rate and hence yield is decreased.

Total water use efficiency, defined as the ratio of economic yield per fed to seasonal water consumption. Accumulated amount of ETo during studying growing seasons, where the highest and lowest values were recorded at Experimental location 2012 and 2013.

Table (1) Metriological data for the growing period in tow studied seasons.

\begin{tabular}{|c|c|c|c|c|c|c|c|c|c|c|c|c|}
\hline \multirow{3}{*}{$\begin{array}{c}\text { Period } \\
\text { day }\end{array}$} & \multicolumn{6}{|c|}{2012} & \multicolumn{6}{|c|}{2013} \\
\hline & \multicolumn{2}{|c|}{$\begin{array}{c}\text { Temperature } \\
{ }^{\circ} \mathrm{C}\end{array}$} & \multicolumn{2}{|c|}{$\begin{array}{c}\text { Relative } \\
\text { humidity } \%\end{array}$} & \multirow{2}{*}{$\begin{array}{c}\text { Wind } \\
\text { speed } \\
\mathrm{m} / \mathrm{sc}\end{array}$} & \multirow{2}{*}{$\begin{array}{c}\text { ETo } \\
\mathrm{mm} / \text { day }\end{array}$} & \multicolumn{2}{|c|}{$\begin{array}{c}\text { Temperature } \\
{ }^{\circ} \mathrm{C}\end{array}$} & \multicolumn{2}{|c|}{$\begin{array}{c}\text { Relative } \\
\text { humidity } \%\end{array}$} & \multirow{2}{*}{$\begin{array}{l}\text { Wind } \\
\text { speed } \\
\mathrm{m} / \mathrm{sc}\end{array}$} & \multirow{2}{*}{$\begin{array}{c}\text { ETo } \\
\mathrm{mm} / \text { day }\end{array}$} \\
\hline & high & low & high & low & & & high & low & high & low & & \\
\hline Jan 5 & 14.5 & 7.4 & 92.1 & 57.1 & 15.9 & 0.9 & 13.8 & 7.8 & 89.3 & 52.5 & 14.2 & 0.9 \\
\hline Jan 11 & 14.5 & 8.6 & 87.6 & 50.0 & 15.1 & 1.3 & 13.8 & 9.1 & 85.0 & 46.0 & 13.4 & 1.3 \\
\hline Feb 10 & 16.5 & 6.7 & 86.5 & 43.2 & 12.4 & 2.0 & 15.7 & 7.0 & 83.9 & 39.7 & 11.0 & 2.0 \\
\hline Feb 10 & 16.2 & 9.3 & 96.9 & 53.6 & 12.5 & 1.9 & 15.4 & 9.8 & 94.0 & 49.3 & 11.1 & 1.9 \\
\hline Feb 8 & 18.9 & 10.8 & 106.3 & 58.4 & 14.8 & 2.1 & 17.9 & 11.3 & 103.1 & 53.8 & 13.2 & 2.1 \\
\hline Marc 10 & 17.6 & 9.7 & 98.7 & 52.3 & 18.2 & 2.4 & 16.7 & 10.2 & 95.7 & 48.1 & 16.2 & 2.4 \\
\hline March 10 & 19.1 & 10.9 & 81.3 & 41.1 & 19.9 & 2.7 & 18.1 & 11.4 & 78.9 & 37.8 & 17.7 & 2.6 \\
\hline March 11 & 20.2 & 10.7 & 94.5 & 45.5 & 13.8 & 2.9 & 19.2 & 11.3 & 91.6 & 41.9 & 12.3 & 2.8 \\
\hline April 10 & 26.6 & 13.2 & 96.4 & 35.5 & 16.2 & 3.4 & 25.3 & 13.9 & 93.5 & 32.7 & 14.4 & 3.3 \\
\hline 10 & 24.3 & 12.9 & 81.9 & 35.7 & 17.3 & 3.5 & 23.1 & 13.5 & 79.4 & 32.8 & 15.4 & 3.5 \\
\hline 10 & 25.4 & 12.9 & 92.8 & 40.8 & 13.7 & 3.9 & 24.1 & 13.5 & 90.0 & 37.5 & 12.2 & 3.8 \\
\hline 8 & 23.7 & 14.4 & 83.6 & 38.3 & 15.0 & 3.4 & 22.5 & 15.2 & 81.0 & 35.3 & 13.4 & 3.3 \\
\hline
\end{tabular}


Authors noticed that from recorded values that high temperature associated with increase relative humidity and wind speed at April which help in increase both evaporation and hence evapotranspiration. So, increase in irrigation water requirement is done.

Fertilizers applied to the irrigation system through injection device (Fig. 1) except super phosphate (15 $\left.\% \mathrm{P}_{2} \mathrm{O}_{5}\right)$, which applied $50 \%$ from needs $(100 \mathrm{~kg} / \mathrm{fed})$ and the rest during the growing season (phosphoric acid $80 \%$ con.) as well as $50 \mathrm{~kg}$ sulphur. Two of fertilizers were used in the experiment as completely soluble $(19 / 19 / 19$ for $\mathrm{N}, \mathrm{P}$ and $\mathrm{K}$ ) and traditional (ammonium sulphate, $20 \% \mathrm{~N}$ and potassium sulphate, $48-50 \%$ $\mathrm{K}_{2} \mathrm{SO}_{4}$ ). In addition to the phosphoric acid that added to complete the rest of the P requirements. Both types modified to fulfil recommended ratio by the Agricultural Extension (unit of 40N, 20P and 30K). Both nitric acid and sulphate potassium $(0,13,43 \% \mathrm{~N}, \mathrm{P}$ and $\mathrm{K}$ ) were used to modified completely soluble fertilizer to face the recommended ratio after Boman and Obreza (2002) and Boman et al (2004)

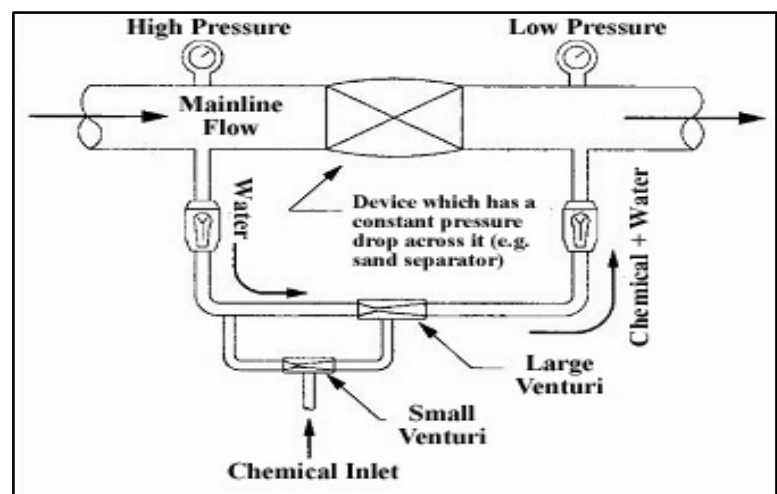

Fig.(1). Chemical injectors based on venture to create adequate pressure differentials for efficient chemical injection.

Water distribution uniformity was carried out for each treatment by selecting 25 emitters from each treatment randomly, before starting the experiment and at the end of the experiments. The discharge rates of the emitters were estimated and emission uniformity was calculated from the following equation according to (Keller and Karameli, 1975) .

Where:

$$
\mathrm{EU}=100 \frac{1}{2}[(\mathrm{Qn} / \mathrm{Qa})+(\mathrm{Qa} / \mathrm{Qx})]
$$

EU $=$ Field emission uniformity, \%

$\mathrm{Qn}=$ The average of the lowest (1/4) of the emitters flow rate, $\mathrm{L} / \mathrm{h}$

$\mathrm{Q} \mathrm{a}=\mathrm{The}$ average of the all emitters flow rate, $\mathrm{L} / \mathrm{h}$; and

$\mathrm{Qx}=$ The average of the highest $(1 / 8)$ of the emitters flow rate, $\mathrm{L} / \mathrm{h}$.

The flow cross section diameter of the long-path emitter was $0.7 \mathrm{~mm}$; discharges $4 \mathrm{~L} / \mathrm{h}$ lateral length was $30 \mathrm{~m}$. Distance between emitters along the lateral was $30 \mathrm{~cm}$. The emitter is considered laminar-flow-type $(\operatorname{Re}<2000)$ (James,1998). Nine emitters from each lateral had been chosen to be evaluated by calculating their clogging ratio at the beginning and at the end of the growing season for both seasons. Three emitters at the beginning, three at middle and three at the end of the lateral were tested for flow rate. Clogging ratio was calculated after El-Berry et al ( 2003) using the following equations:

$\mathrm{E}=\mathrm{qu} / \mathrm{qn} \times 100$

$\mathrm{CR}=(1-\mathrm{E}) \times 100$

where:

$\mathrm{E}=$ the emitter discharge efficiency, $(\%)$

$\mathrm{qu}=$ emitter discharge, at the end of the growing season $(\mathrm{L} / \mathrm{h})$

$\mathrm{qn}=$ emitter discharge, at the beginning of the growing season $(\mathrm{L} / \mathrm{h})$

$\mathrm{CR}=$ the emitter clogging ratio, $(\%)$

\section{Results And Discussion}

Superphosphte was applied to the experimental site during preparation and before planting due to phosphorus is highly immobile in soil; usually transport and uptake of phosphorus are regulated by diffusion, which limits the phosphorus uptake (Kargbo et al., 1991).

\section{Drip irrigation clogging:}

Clogging values under traditional fertilizers could be arranged in ascending order as follow: $2 / 3<3 / 4<$ $1 / 2$. This finding could attributed to the rest of irrigation water which used to leach (flush ) the irrigation system although $1 / 2$ fertigation time was the highest value and had $50 \%$ from irrigation quantity to flush the system but 
half time of fertigation not enough to inject fertilizer without impurities. Regarding to the completely soluble treatment, fertigation were less than tradition ones and could be arranged in descending order as follow: $3 / 4>2 / 3>1 / 2$ fertigation treatments. This results due to mainly to quantity of rest of irrigation water that not enough to leach the irrigation system (EL-Gindy, et al., 2009 and Fares and Abbas. 2009). Also results showed that regardless fertigation time, completely soluble fertilizer was superior and had a lowest values in clogging determination which mainly due to decrease the impurities materials.

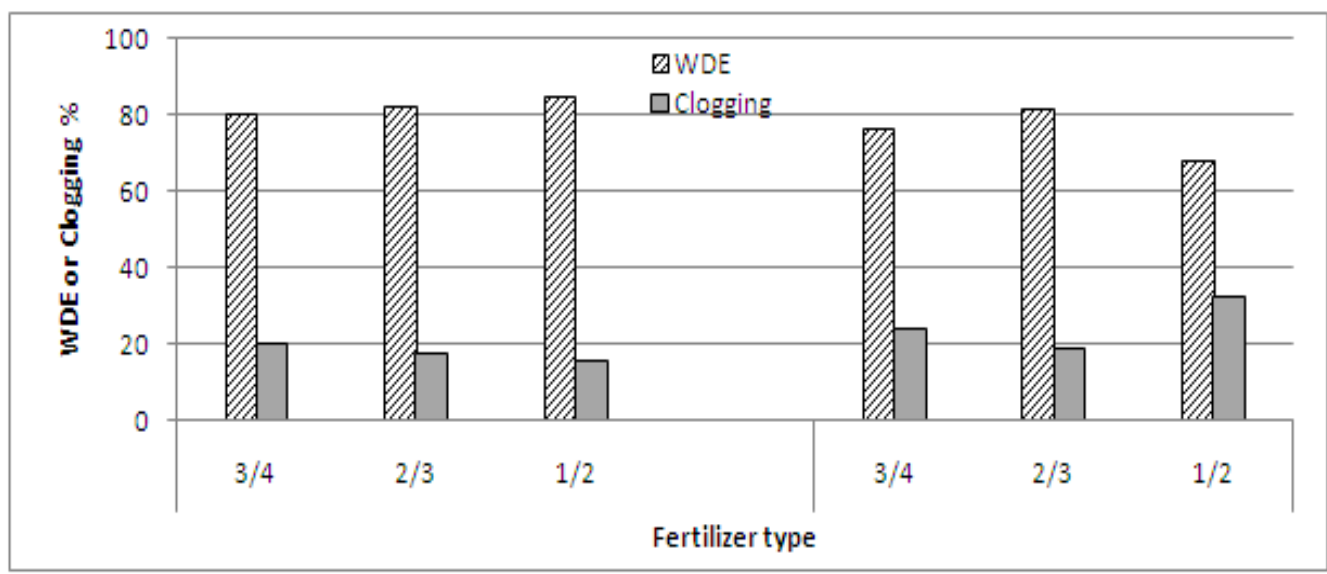

Fig. (2) Effect of fertilizer type and fertigation time on water distribution efficiency (WDE) and clogging.

Meanwhile, under drip irrigation system, the liquid fertilizers lead to improve water distribution efficiency (WDE) from 80 to $84.1 \%$ as shown in (Table 2 and Fig. 2). The decrease in WDE may be due to physical change that happened if the short fertigation time (1/2) led to increase both density and viscosity, which lead to increase friction losses in lateral and hence decrease emitter discharge. This due to lowering irrigation water $\mathrm{pH}$ and consequently, preventing the salts perception inside the laterals or emitters (Sagi, 1990and Sabreen et al., 2009) .

Table (2) Effect of fertilizer type and fertigation schedule on snap bean yield and water use efficiency in drip irrigated sandy soil.

\begin{tabular}{|c|c|c|c|c|c|c|}
\hline \multirow[t]{2}{*}{ Fertilizer type } & \multirow{2}{*}{$\begin{array}{c}\text { Fertigation/irrigation } \\
\text { time ratio }\end{array}$} & \multirow{2}{*}{$\begin{array}{l}\text { Total yield } \\
\text { (ton/fed.) }\end{array}$} & \multicolumn{2}{|c|}{$\begin{array}{l}\text { Irrigation water requirements } \\
\left(\mathrm{m}^{3} / \mathrm{season}\right)\end{array}$} & \multicolumn{2}{|c|}{$\begin{array}{l}\text { Water use efficiency } \\
\qquad\left(\mathrm{kg} / \mathrm{m}^{3}\right)\end{array}$} \\
\hline & & & Consumed & Calculated & Consumed & Calculated \\
\hline \multirow{4}{*}{$\begin{array}{l}\text { Completely } \\
\text { soluble }\end{array}$} & $3 / 4$ & 4.93 & \multirow{8}{*}{1720} & \multirow{8}{*}{1242} & 2.866 & 4.03 \\
\hline & $2 / 3$ & 4.40 & & & 2.558 & 3.59 \\
\hline & $1 / 5$ & 4.25 & & & 2.471 & 3.47 \\
\hline & & 4.53 & & & 2.63 & 3.70 \\
\hline \multirow{4}{*}{$\begin{array}{l}\text { Traditional } \\
\text { fertilizer }\end{array}$} & $3 / 4$ & 3.52 & & & 2.047 & 2.88 \\
\hline & $2 / 3$ & 3.75 & & & 2.180 & 3.06 \\
\hline & $1 / 5$ & 3.00 & & & 1.744 & 2.45 \\
\hline & & 3.42 & & & 1.99 & 2.80 \\
\hline LSD 5\% & & 0.32 & & & 0.24 & 1.11 \\
\hline
\end{tabular}

Data presented in table (2) show that drip irrigated snap bean yield increased by using completely soluble fertilizers comparing with the traditional fertilizers.

Fig. (3) illustrate the regression analysis between the main factor under investigation snap bean yield and fertigation time. One can notice that highly positively relation was obtained between them with highly correlation $\left(0.956^{* *}\right)$, so in order to maximize utilization from used fertilizers, time of fertigation must be taken in consider. Also, it is clear that highly soluble fertilizer when time of fertigation resembles $3 / 4$ from irrigation time fulfil the maximum yield. It is worthy to mention that traditional fertilizers because it took much time for solubility first before fertigation process and took also much water in tank (Burt et al., 1998). 


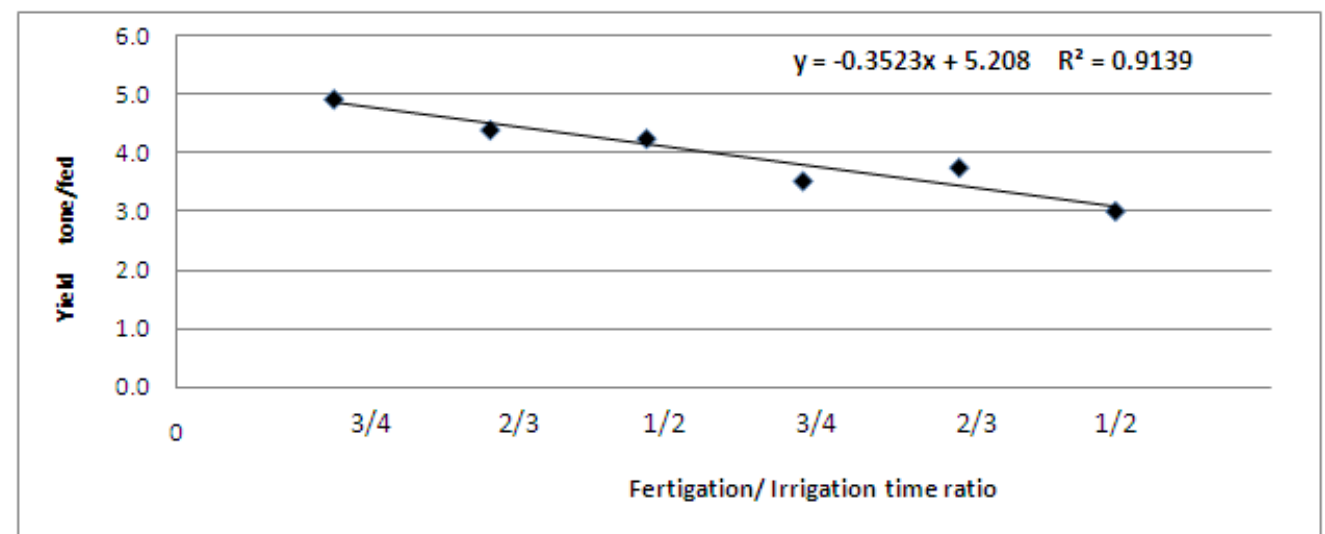

Fig. 3 Relation between yield of snap bean and fertigation time regardless fertilizer types.

\section{Snab bean yield:}

Economic yield is a part of the total biological yield of the crop and hence snap bean production is an important determinant of the economic yield. The total yield at final harvest was significantly higher in completely soluble fertilizers ( 4.52 ton/fed) over traditional one (3.42 ton/fed) (Table 2$)$. This means that there was a significant increase resulted from using completely soluble fertilizers by about $32.5 \%$ over traditional ones. Further, significantly higher yield was observed with increasing fertigation time, where increasing fertigation time by about 10 minutes increased yield by about $12 \%$ (from $2 / 3$ to $3 / 4$ fertigation time) under completely soluble fertilizers. Whereas under traditional ones, the opposite was true and the reduction was 6.5 $\%$ in same sequence. Also, data noticed that injection fertilizer period $3 / 4$ was superior under completely soluble fertilizers while $2 / 3$ fertigation time was the best under traditional ones.Similar results of improved yield have been reported by Ibrahim (1992).

\section{Water use efficiency:}

Data obtained revealed that there were two water requirements as calculate one (from climatology data) and actual one (consumed). Of course the actual irrigation requirement $\left(1720 \mathrm{~m}^{3} / \mathrm{season}\right)$ was higher than the calculated one $\left(1242 \mathrm{~m}^{3} / \mathrm{season}\right)$ and the increase percentage was $42 \%$. Son there are two water use efficiency (WUE) that recorded in the table (2). Data observed that there was a negative correlation between time of fertigation and WUE values especially under completely soluble fertilizers. But under traditional fertilizers the highest value of WUE was obtained with fertigation time $2 / 3$ and the lowest one was recorded at fertigation at $1 / 2$ irrigation time.

Regardless fertigation time, completely soluble fertilizers has a superior effect on WUE value ( $2.63 \mathrm{~kg}$ yield $/ \mathrm{m}^{3}$ irrigation water) than traditional one (1.99 $\mathrm{kg}$ yield $/ \mathrm{m}^{3}$ irrigation water). The percentage of the change in WUE as a result of completely soluble fertilizers was $32.1 \%$ over traditional one. Same trend was obtained in case of WUE values on base of calculated water requirement.

Table (3) Effect of fertilizer types and fertigation time on the fertilizer use efficiency

\begin{tabular}{|c|c|c|c|c|}
\hline \multirow{2}{*}{ Fertilizer type } & \multirow{2}{*}{$\mathrm{N}$} & \multicolumn{2}{|c|}{$\mathrm{P}$} \\
\cline { 2 - 5 } & Fertigation/ Irrigation time ratio & \multicolumn{3}{|c|}{ Kg yield / fertilizer unit } \\
\hline \multirow{3}{*}{ Completely soluble } & $3 / 4$ & 123.25 & 0.25 & 4.11 \\
\cline { 2 - 5 } & $2 / 3$ & 110.00 & 0.22 & 3.67 \\
\cline { 2 - 5 } & $1 / 2$ & 106.25 & 0.21 & 3.54 \\
\cline { 2 - 5 } & & 113.17 & 0.23 & 3.77 \\
\hline \multirow{3}{*}{ Traditional fertilizer } & $3 / 4$ & 88.00 & 0.18 & 2.93 \\
\cline { 2 - 5 } & $2 / 3$ & 93.75 & 0.19 & 3.13 \\
\cline { 2 - 5 } & $1 / 2$ & 75.00 & 0.15 & 2.50 \\
\hline & & 3.58 & 0.17 & 2.85 \\
\hline
\end{tabular}

\section{Fertilizers use efficiency:}

According to the effect of fertilizers type and fertigation time on fertilizer use efficiency (FUE) of snap bean plants, one can notice that the highest and lowest values of N, P and K. Table (3) illustrated the effect of both fertilizer types and fertigation time (relative to the irrigation time) on FUE for macronutrients (N, P and K) as a unit to produce $\mathrm{kg}$ economic yield of snap bean. Data noticed that decrease in fertigation time was associated with decrease in FUE for the studied macronutrients, except under traditional fertilizer types, where fertigation during $2 / 3$ irrigation time was the best one followed by the highest fertigation time ( $3 / 4$ from irrigation time). Also, results showed that FUE values under completely soluble fertilizer are higher than the 
traditional one. Similarly in fertigation, applied fertilizer through the drip system is placed to the active plant root zone and improves fertilizer use efficiency Navalawala, 1991.

Regardless to the fertigation time, completely soluble fertilizer's FUE were higher than traditional one and the percentage of the increase were 32, 35 and $32 \%$ for FUE of N, P and K unites. While eliminate fertilizer type, fertigation period has a superior effect on FUE for the studied macronutrients for $3 / 4$ is the best one followed by $2 / 3$ and $1 / 2$ from irrigation time. Also, one can notice that there is no significant difference between FUE for $\mathrm{P}$ at fertigation time $3 / 4$ and $2 / 3$ from irrigation time.

Under completely soluble fertilizers the percentage of the increase in FUE were 12, $16 \%$ (comparing $3 / 4$ with $2 / 3$ and $1 / 2$ ) and $3.5 \%$ comparing $2 / 3$ with $1 / 2$ fertigation time for $\mathrm{N}$. Whereas, the percentage of the increase in FUE values were 13.6, 19.0, 4.8; 12.0, 16.0 and $3.7 \%$ for $\mathrm{P}$ and $\mathrm{K}$ in same sequences. But another trend was obtained under traditional fertilizers, where $2 / 3$ fertigation time was the highest values followed by $3 / 4$ then $1 / 2$. The increase in FUE for $2 / 3$ fertigation time above $3 / 4$ and $1 / 2$ were $6.5,25 ; 5.6,26.7$ and 6.8 and $25.2 \%$, respectively.

Regardless fertilizers type, FUE values of ferigation time could arrange in descending order as follow: $3 / 4>2 / 3>1 / 2$ for $\mathrm{N}, \mathrm{P}$ and $\mathrm{K}$ fertilizers. The percentage of the increase in FUE under fertigation time $3 / 4$ comparing with $2 / 3$ and $1 / 2$ were $3.6,16.6,5.0,16.7$ and 3.5 and $16.6 \%$ for $\mathrm{N}, \mathrm{P}$ and $\mathrm{K}$, respectively.

Agricultural grade fertilizers are generally not suitable for use in fertigation systems because of the amount of impurities present, which may be insoluble and lead to dripper blockages. For this reason technical grade fertilisers are normally required in fertigation systems because they have fewer impurities and proportionally higher levels of the desired mineral nutrients (Ibrahim, 1992. and EL-Gindy et al 2009).

\section{Conclusion}

The use of fertigation is gaining popularity because of its efficiencies in nutrient management, time and labour and potentially a greater control over crop performance. Fertigation potentially offers many advantages over conventional approaches to managing a crop's fertilizer needs. While fertigation is an exciting and potentially profitable addition to horticultural production systems, it also requires significant investment in equipment, advanced management skills, constant monitoring and an understanding of the specific crop's nutrient needs. The use of acidic fertilizers temporarily unclogs the system emitters. The irrigation and chemical injection systems should be thoroughly washed and flushed with fresh water, especially after the injection of acids into the system.

\section{Reference}

[1]. Boman, B., and T. Obreza. 2002. Fertigation nutrient sources and application considerations for citrus, University of Florida, IFAS Circular 1410. http://edis. ifas.ufl.edu/CH185.

[2]. Boman, B., S. Shukla, and D. Haman. 2004. Chemigation equipment and techniques for citrus. University of Florida, IFAS Circular 1403.http://edis.ifas.ufl.edu/CH184.

[3]. Burt, C., K. O’Connor, and T. Ruehr. 1998. Fertigation. California Polytechnic State University San Luis Obispo, Irrigation Training and Research Center.295 p.

[4]. Charles M.(2007). Fertigation chemicals, FERTIGATION.295 pp.

[5]. EL-Gindy, A. M, M. Y. Tayel, K. F. EL-Bagoury, and KH. A. Sabreen .2009. Effect of injector types, irrigation and nitrogen treatments on emitters clogging; MisrJ.Ag. Eng., Vol. 26(3):pp. 1263-1275.

[6]. FAO( 2005)Fertilizer use by crop in Egypt, First version, published by FAO, Rome. 57pp.

[7]. Fares, A., and F. Abbas. 2009. Irrigation systems and nutrient sources for irrigation. University of Hawai'I at Mānoa, College of Tropical Agriculture and Human Resources, publication SCM-25.http://www.ctahr. hawaii.edu/oc/freepubs/pdf/SCM-25.pdf.

[8]. Hochmuth, G.J., 1992. Fertilizer management for drip-irrigated vegetables in Florida. Hort. Technol. 2, $27-32$.

[9]. Ibrahim, A., 1992. Fertilization and irrigation management for tomato production under arid conditions. Egyptian J. Soil Sci. 32 (1), 81-96.

[10]. Kargbo, D.J. Skopp and D. Knudsen, 1991. Control of nutrient soils, sediments, residuals, and waters. Southern cooperative series. Agron. J., 83:1023-1028

[11]. Li, F.M., Q.H. Song, H.S. Liu, F.R. Li and X.L. Liu, 2001. Effects of pre-sowing irrigation and phosphorus application on water use and yield of spring wheat under semi-arid conditions. Agric. Water Manage., 49: 173-183.

[12]. Locascio, S.J., and A.G. Smajstrla. 1995. Fertilizer timing and pan evaporation scheduling for drip irrigated tomato. In Lamm (ed.) Microirrigation for a Changing World: Conserving Resources/Preserving the Environment. ASAE Publ. 4-95. pp. 175-180.

[13]. Ould Ahmed B.A., Yamamoto T, Inoue M. and H. Anyoji, 2006. Drip irrigation schedules with saline water for sorghum under greenhouse condition. Trans JSIDRE 244:133-141

[14]. Raun W.R., J.B. Solie, G.V. Johnson, M.L. Stone, R.W. Mullen, K.W. Freeman, W.E. Thomason, and E.V. Lukina. 1999.Improving Nitrogen Use Efficiency in Cereal Grain Production with Optical Sensing and Variable Rate Application .Agron. J. 94:815-820.

[15]. Sabreen .Kh. A. P., K. F. El-Bagoury, M. Y. Tayel, and A. M. El-Gindy. 2009. Hydraulic performance of fertigation applicators ; Journal Biol. Chem. Environ. Sci., 4 (1) : pp. 1049-1065.

[16]. Sagi, G., 1990, Water quality and clogging of irrigation systems in Israel in 1989, Water and Irrigation Bull. (in Hebrew), 280:57-61

[17]. Sarkar, S., S.R. Singh and Y. Singh, 2000. Effective use of harvested water in relation to productivity and water use pattern of Rajmash as an inter-crops. J. Indian Soc. Soil Sci., 48:824-826.

[18]. Tayel M.Y., Sabreen K. P., H. A. Mansour, 2013. Effect of drip irrigation method, nitrogin source, and flushing schedule on emitter clogging. Agric. Sci., 4(3): 131-137. 